\title{
Signaling through TLR5 mitigates lethal radiation damage by neutrophil-dependent release of MMP-9
}

Craig M. Brackett $\mathbb{D}^{1 凶}$, Kellee F. Greene ${ }^{1}$, Alyssa R. Aldrich ${ }^{1}$, Nicholas H. Trageser ${ }^{1}$, Srabani Pal ${ }^{1}$, Ivan Molodtsov ${ }^{2}$, Bojidar M. Kandar ${ }^{1}$, Lyudmila G. Burdelya', Scott I. Abrams (iD ${ }^{3}$ and Andrei V. Gudkov (D) ${ }^{1}$

(c) The Author(s) 2021

Acute radiation syndrome (ARS) is a major cause of lethality following radiation disasters. A TLR5 agonist, entolimod, is among the most powerful experimental radiation countermeasures and shows efficacy in rodents and non-human primates as a prophylactic (radioprotection) and treatment (radiomitigation) modality. While the prophylactic activity of entolimod has been connected to the suppression of radiation-induced apoptosis, the mechanism by which entolimod functions as a radiomitigator remains poorly understood. Uncovering this mechanism has significant and broad-reaching implications for the clinical development and improvement of TLR5 agonists for use as an effective radiation countermeasure in scenarios of mass casualty resulting from accidental exposure to ionizing radiation. Here, we demonstrate that in contrast to radioprotection, neutrophils are essential for the radiomitigative activity of entolimod in a mouse model of lethal ARS. Neutrophils express functional TLR5 and rapidly exit the bone marrow (BM), accumulate in solid tissues, and release MMP-9 following TLR5 stimulation which is accompanied by an increase in the number of active hematopoietic pluripotent precursors (HPPs) in the BM. Importantly, recombinant MMP-9 by itself has radiomitigative activity and, in the absence of neutrophils, accelerates the recovery of the hematopoietic system. Unveiling this novel TLR5-neutrophil-MMP-9 axis of radiomitigation opens new opportunities for the development of efficacious radiation countermeasures to treat ARS following accidental radiation disasters.

Cell Death Discovery (2021)7:266; https://doi.org/10.1038/s41420-021-00642-6

\section{INTRODUCTION}

Exposure to ionizing radiation causes significant DNA damage in many cells of the organism and is the underlying cause of multiple pathologies including acute radiation sickness (ARS). They can occur either accidentally (i.e., nuclear disasters like Chernobyl of Fukushima catastrophes) or intentionally (i.e., cancer therapies) and require the development of countermeasures that can reduce the severity of ARS and improve recovery and survival. Such countermeasures are classified as either protectants when given prophylactically prior to intentional radiation or mitigators when administered therapeutically after radiation exposure [1].

The development of protectors has been more successful than radiomitigators. The only FDA-approved powerful radioprotective drug, an antioxidant amifostine, has no efficacy as a radiomitigator [2]. In fact, dramatic cell loss in the hematopoietic system (HPS) due to p53-mediated apoptosis induced by DNA damage occurs within the first few hours after radiation exposure $[3,4]$ and renders radioprotective agents completely ineffective. Similarly, agents that induce proinflammatory cytokines (e.g., TNF, IL-12) $[5,6]$ are another well-studied class of efficacious radioprotectants that commonly act as activators of a pro-survival p53-suppressive NF-KB pathway [7].
Efficacious radiomitigators engage mechanisms of tissue regeneration and reduce the risk of sepsis and bleeding rather than suppressing apoptosis [8]. The only class of FDA-approved drugs for such indications are derivatives of G-CSF (Neupogen and Neulasta) commonly used in oncology to accelerate the recovery of hematopoiesis following chemotherapy-associated myelosuppression [1]. Unfortunately, the efficacy of these G-CSF-based drugs is rather weak, and they require multiple administrations under conditions of supportive clinical care [9-11] and do not satisfy the needs of mass casualty scenarios. Thus, the development of potent yet feasible mitigating countermeasures remains a strong unmet medical need.

To that end, our prior work defined bacterial flagellin, the sole toll-like receptor (TLR) 5 agonist, as a superior radioprotectant when compared to amifostine for suppressing apoptosis in radiosensitive tissues [12]. We developed a pharmacologically optimized flagellin derivative, entolimod, as a powerful radioprotector in mice and non-human primates but, unlike amifostine, did not diminish the radiosensitivity of tumors [12]. Moreover, entolimod appeared to be an effective radiomitigator in rodent and non-human primate models of lethal ARS caused by total body irradiation (TBI). A single dose of entolimod with no supportive care rescued animals when administered within $48 \mathrm{~h}$

\footnotetext{
'Department of Cell Stress Biology, Roswell Park Comprehensive Cancer Center, Buffalo, NY 14263, USA. ${ }^{2}$ I.V. Davydovsky Clinical City Hospital, Moscow Department of Healthcare, Moscow, Russian Federation. ${ }^{3}$ Department of Immunology, Roswell Park Comprehensive Cancer Center, Buffalo, NY 14263, USA. ${ }^{凶}$ email: craig.brackett@roswellpark.org Edited by Dr. Ivano Amelio
}

Received: 26 July 2021 Revised: 13 August 2021 Accepted: 19 August 2021

Published online: 28 September 2021 
post-TBI $[13,14]$ thus exceeding the efficacy of G-CSF-based drugs. Remarkably, entolimod also showed efficacy in other pre-clinical models of both genotoxic [15-17] and non-genotoxic stressors [18-20].

While entolimod-induced radioprotection is well-known to involve a combination of anti-apoptotic, anti-oxidative, and antibacterial effects elicited by the liver [12, 19], the mechanism of radiomitigation remains poorly understood. Uncovering this mechanism could guide the development of more effective and safe countermeasures to treat patients with ARS. To determine the mechanism by which entolimod mitigates radiation damage, we focused on the cellular effectors of its function. In our prior studies of anticancer immunotherapeutic effects of entolimod, we observed a profound neutrophil $(N \phi)$ response as one of the earliest cellular consequences of systemic TLR5 activation characterized by release from the BM, rapid exit from the blood, and recruitment to tissues [19]. This $N \phi$ response was defined as one of three biomarkers of efficacy for entolimod, along with increased systemic levels of G-CSF and IL-6 [13, 14].

Since entolimod presumably mitigates radiation damage by improving HPS recovery and the release of matrix metalloproteinase-9 (MMP-9) by $\mathrm{N} \phi$ has been linked to stimulating hematopoiesis [21], we hypothesized that entolimod mitigates radiation damage to the HPS through $\mathrm{N} \phi$-dependent release of MMP-9. Using a mouse model of lethal ARS induced by TBI to test this hypothesis, we found that $\mathrm{N} \phi$ (i) are essential mediators of the radiomitigative but not radioprotective abilities of entolimod, (ii) express functional TLR5 but undergo minimal transcriptional changes post-entolimod suggesting that $\mathrm{N} \phi$ mitigate ARS through a transcriptional-independent mechanism; and (iii) increase the number of active hematopoietic pluripotent precursors (HPPs) in bone marrow, which can be mimicked by administration of recombinant pro-MMP-9 (rMMP-9) in the absence of $\mathrm{N} \phi$. These results define the release of MMP- 9 by $\mathrm{N} \phi$ as a major contributor, along with G-CSF and IL-6 [14], as mediators of radiomitigation post-entolimod by increasing the number of active HPPs to facilitate recovery of a damaged HPS. Altogether, these data underscore the potential use of MMP-9 to compensate for the shortcomings of currently approved radiation countermeasures.

\section{RESULTS \\ $\mathrm{N} \phi$ are essential mediators of the radiomitigative but not radioprotective abilities of entolimod}

Identification of $\mathrm{N} \phi$ as one of three biomarkers of entolimod's efficacy as a radiation countermeasure [13] prompted us to determine whether $\mathrm{N} \phi$ are cellular mediators of radioprotection and radiomitigation. We accomplished this using a loss-offunction approach to deplete $\mathrm{N} \phi$ in vivo using the wellaccepted a-Ly6G antibody [22], which effectively depletes $\mathrm{N} \phi$ by at least $95 \%$ (Supplementary Fig. S1), prior to entolimod administration in the radioprotective (Fig. 1A) and radiomitigative (Fig. 1E) schemes similarly used by us [12-16, 19].

In the radioprotection scheme, entolimod protected inbred BALB/C (Fig. 1B) and outbred NIH-S (Supplementary Fig. S2A) mice from lethal ARS both in the presence (rat IgG) and absence ( $a-$ Ly6G) of $\mathrm{N} \phi$. Consistently, $\mathrm{N} \phi$ depletion did not diminish the ability of entolimod to protect the number of total HPPs as measured by MethoCult in both BALB/C (Fig. 1C) and NIH-S (Supplementary Fig. S2B) mice. Moreover, the number of stem cell populations in the BM of BALB/C (Fig. 1D) and NIH-S (Supplementary Fig. S2C) mice recovered in the presence and absence of $\mathrm{N} \phi$ and was remarkably similar to stem cell numbers in control mice that did not receive TBI. Thus, the radioprotective ability of entolimod does not depend on $\mathrm{N} \phi$.

In stark contrast to radioprotection, $\mathrm{N} \phi$ depletion in BALB/C mice abrogated the radiomitigative activity of entolimod (Fig. 1F).

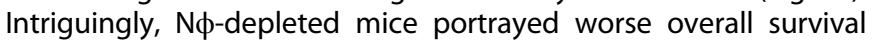

than mice with $\mathrm{N} \phi$ suggesting a critical role for $\mathrm{N} \phi$ in the global response of an organism to radiation damage. The absence of $\mathrm{N} \phi$ also prevented the recovery of both total BM HPPs and granulocyte/macrophage (G/M) progenitors (Fig. 1G). Collectively, these data show that entolimod facilitates radioprotection and radiomitigation through distinct mechanisms, whereby, $\mathrm{N} \phi$ are essential for the radiomitigative but not radioprotective activities of entolimod.

\section{Entolimod augments $\mathrm{N} \phi$ recruitment and expression of homing molecules}

We next sought to perform a more comprehensive analysis of $\mathrm{N} \phi$ recruitment to tissues post-entolimod, since our prior work only evaluated the release of $\mathrm{N} \phi$ from the $\mathrm{BM}$ and recruitment to the liver [19]. At $2 \mathrm{~h}$ post-entolimod, $\mathrm{N} \phi$ exited both the BM and the blood and were also recruited to all tissues examined except for the spleen (Fig. 2A). At $5 \mathrm{~h}$ post-entolimod, increased $\mathrm{N} \phi$ recruitment was still observed in many tissues examined (including the liver, lungs, heart, and kidneys) in addition to the blood and spleen. Adoptively transferred $\mathrm{N} \phi$ were also similarly released from the BM and recruited to the liver and lungs, two of the most prominent sites of recruitment post-entolimod treatment (Fig. 2B). These results indicate that entolimod stimulates $\mathrm{N} \phi$ release from the BM and recruitment to tissues through a bloodborne homing mechanism.

Since $\mathrm{N} \phi$ differentiation occurs across a linear path from pre-N $\phi$ and then to immature and mature $N \phi$ [23], we sought to understand whether entolimod stimulates the release of certain $\mathrm{N} \phi$ populations from the BM. Entolimod only causes a drop in the number of mature $\mathrm{N} \phi$ (Fig. $2 \mathrm{C}$, left), indicating a preferential release of this $\mathrm{N} \phi$ population. Entolimod also changes the composition of the $\mathrm{N} \phi$ population in the $\mathrm{BM}$ as observed by a decrease in mature $N \phi$ and an increase in the percentages of both pre- and immature $\mathrm{N} \phi$ (Fig. $2 \mathrm{C}$, right). Thus, entolimod stimulates the release of mature $\mathrm{N} \phi$ from the $\mathrm{BM}$ which, in turn, triggers differentiation of both pre-N $\phi$ and immature $\mathrm{N} \phi$.

Because reliable commercially available antibodies to detect TLR5 do not exist, we developed a flow cytometry-based "sandwich" platform that utilizes biotinylated-entolimod (b-entolimod) and a streptavidin-conjugated fluorochrome in combination with antibodies to identify which immune cell subsets express TLR5. Using this approach, and for additional specificity, we compared TLR5 expression in TIr $5^{W T / W T}$ vs. T/r $5^{-/-}$mice. We found that $\mathrm{N} \phi$ from the blood of wild-type mice are the only immune cells that bound b-entolimod (Fig. 2D). Importantly, $\mathrm{N} \phi$ from $\mathrm{Tlr} 5^{-/}$

mice did not display staining, demonstrating that this approach specifically detects TLR5 expression. These results are consistent with prior observations showing that N $\phi$ express TLR5 [24].

We lastly sought to determine whether TLR5 signaling through MyD88, the canonical adapter for TLR signaling [25], downregulates L-selectin and upregulates CD11b on $\mathrm{N} \phi$ in order to support adhesion to the endothelium and extravasation from the bloodstream into tissues [26-29]. Indeed, L-selectin was downregulated and $\mathrm{CD} 11 \mathrm{~b}$ was upregulated on $\mathrm{N} \phi$ as early as $10 \mathrm{~min}$ postentolimod and lasted for at least 120 min (Supplementary Fig. S3A). Near-complete abrogation of L-selectin downregulation and CD11b upregulation post-entolimod was observed in $M y d 88^{-1-} \mathrm{N} \phi$, which

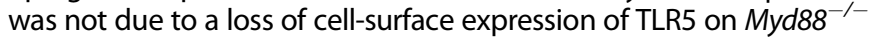
$\mathrm{N} \phi$ (Supplementary Fig. S3B) and is consistent with prior observations using a TLR4 agonist [30]. Entolimod-treated N $\phi$ had improved binding to endothelial cells and was significantly higher when both $\mathrm{N} \phi$ and endothelial cells were pretreated with entolimod (Supplementary Fig. S3C). Lastly, blocking either L-selectin or ICAM-1, the ligand for CD11b, with antibodies, significantly attenuated $\mathrm{N} \phi$ recruitment to the liver (Supplementary Fig. S3D). Taken together, these data demonstrate that entolimod stimulates $\mathrm{N} \phi$ recruitment to tissues by triggering MyD88-dependent L-selectin downregulation and CD11b upregulation. 

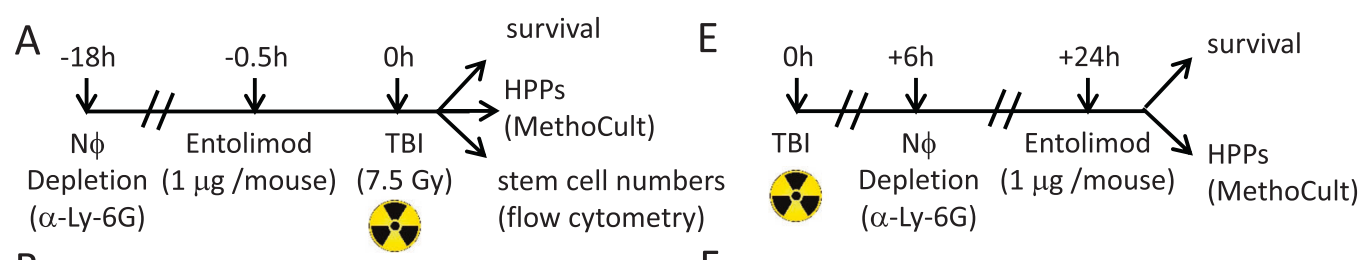

B

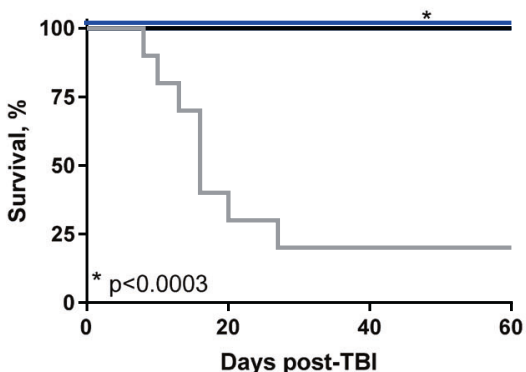

$F$

- rat IgG + Vehicle $(\mathrm{N}=10)$

- rat Ig $G+$ entolimod $(\mathrm{N}=10)$

C

- $\alpha-$-Ly-6G + entolimod ( $N=10)$

Total HPPs

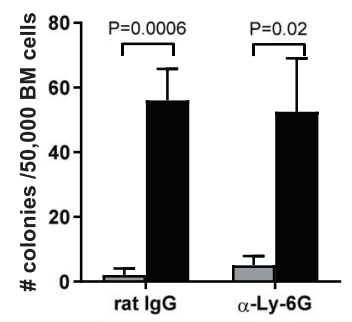

D Vehicle entolimod

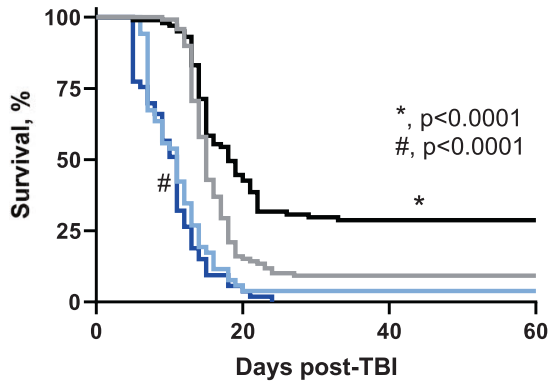

$$
\begin{aligned}
& \text { - rat } \lg G+\text { Vehicle }(N=119)-\alpha-L y-6 G+\text { Vehicle }(N=52) \\
& - \text { rat } \lg G+\operatorname{entolimod}(N=101)-\alpha-L y-6 G+\operatorname{entolimod}(N=53)
\end{aligned}
$$

G
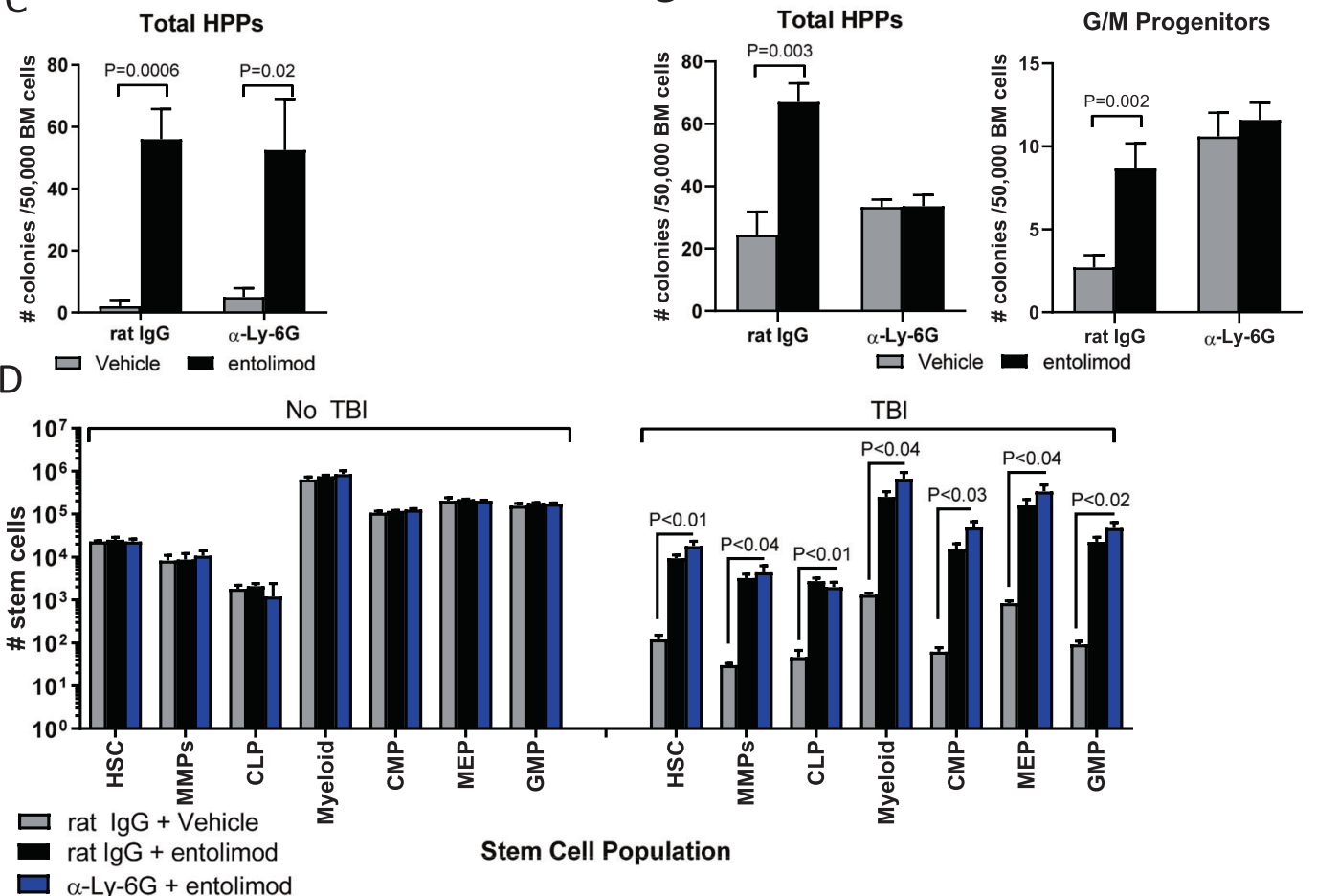

No TBI

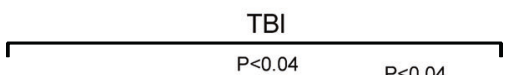

TBI

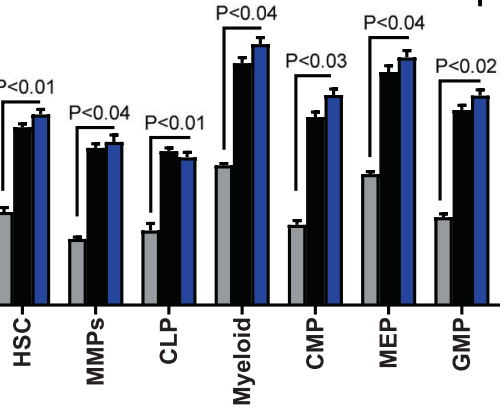

Stem Cell Population

Fig. $1 \mathrm{~N} \phi$ mediate the radiomitigative but not radioprotective abilities of entolimod. Experimental layouts to determine the role of $\mathrm{N} \phi$ in the $\mathbf{A}$ radioprotective and $\mathbf{E}$ radiomitigative effects of entolimod in BALB/C mice. Survival by Kaplan-Meier curves in mice treated with entolimod in the presence (rat IgG) or absence $(\alpha-\mathrm{Ly}-6 \mathrm{G})$ of $\mathrm{N} \phi$ in the $\mathbf{B}$ radioprotective and $\mathbf{F}$ radiomitigative schemes. $P$-values were determined by Log-rank test. Measurement of total HPPs and granulocyte/macrophage (G/M) progenitors in BM by MethoCult in the C radioprotective ( $n=4-5$ mice /group) and G radiomitigative $(n=3-10$ mice/group) schemes. Total HPPs were measured $+1 \mathrm{~h}$ post-TBI for radioprotection and for radiomitigation, both total HPPs and G/M progenitors $+3 d$ post-treatment with vehicle or entolimod. D Absolute number of stem cell populations in BM by flow cytometry in the presence (rat lgG) and absence $(\alpha-L y-6 \mathrm{G})$ of N $\phi$ on day 8 post-TBI in the radioprotection scheme $\left(n=3-5\right.$ mice/group). Stem cell populations were defined as follows: HSC (Lineage ${ }^{-}$Flt $^{-}{ }^{-}$c-kit ${ }^{+}$Sca- $^{+}{ }^{+}$), MMP

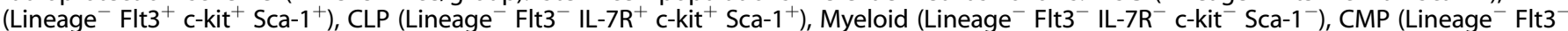
IL-7R ${ }^{-}$CD34 $^{+} \mathrm{CD} 16 / 32^{-}$), MEP (Lineage ${ }^{-}$Flt3 $^{-}$IL-7R $^{-}$CD34 ${ }^{-}$CD16/32 ${ }^{-}$), and GMP (Lineage ${ }^{-}$Flt3 $^{-}$IL-7R $^{-}$CD34 $^{+}$CD16/32 $^{+}$). Error bars represent mean \pm SEM; $P$-values were determined by Student's $t$-test.

\section{Activation of TLR5 on Nф and non-hematopoietic cells cooperate to mitigate radiation damage}

Expression of functional TLR5 on both $\mathrm{N} \phi$ (Fig. 2D) and nonhematopoietic cells (i.e., hepatocytes) [19] prompted us to determine the relative contribution of both cell populations to the radiomitigative activities of entolimod. To do this, we performed TIr $5^{\text {WT/WT }}$ (wild-type) or Tlr5 $5^{-1-} \mathrm{N} \phi$ transfers in Tlr5 $5^{-/-}$ bone marrow chimeras so that (i) both cell populations expressed TLR5 (wild-type $\mathrm{N} \phi$ into $T / r 5^{-/-} \mathrm{BM} \rightarrow$ wild-type chimeras); (ii) neither cell population expressed TLR5 $\left(T / r 5^{-/-} \mathrm{N} \phi\right.$ into $T / r 5^{-/-}$ 

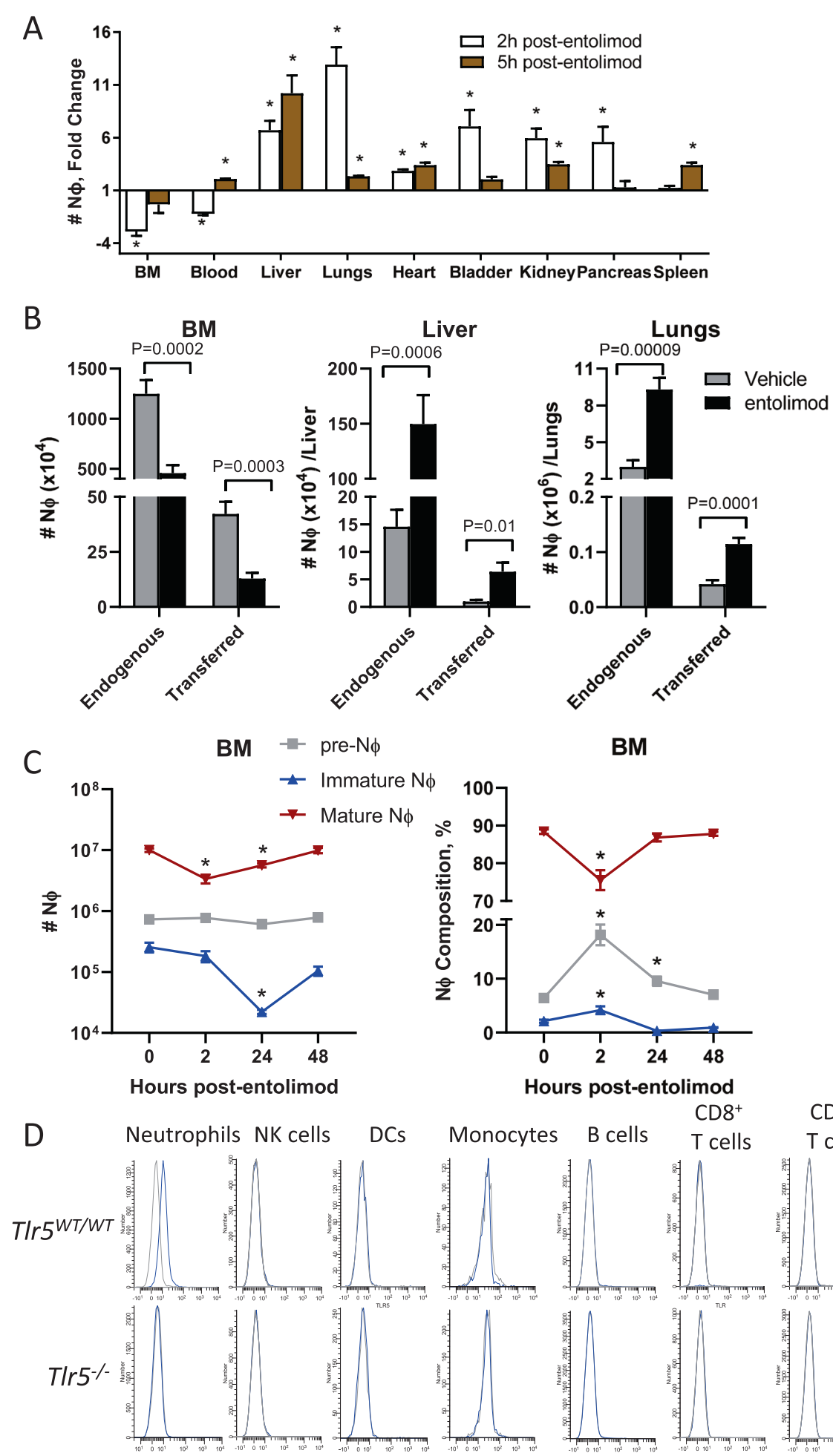

BM
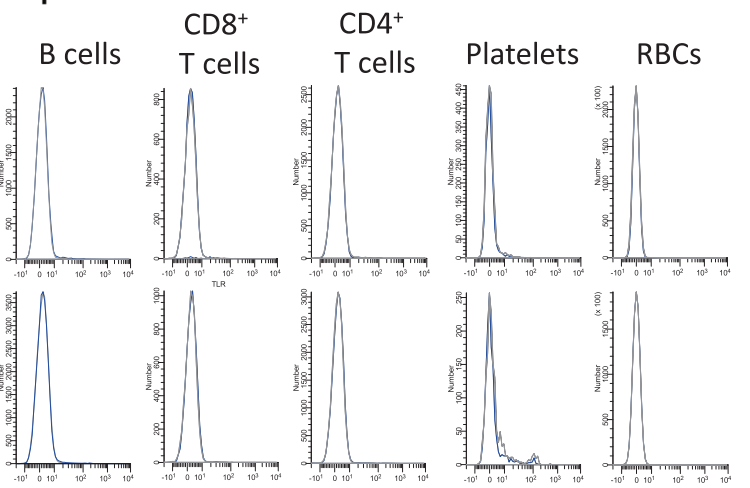

Fig. 2 Entolimod stimulates $\mathbf{N} \phi$ recruitment to tissues and differentiation. A Fold change in the $\mathrm{N} \phi$ response in the indicated organs calculated from the absolute number of $\mathrm{N} \phi$ in entolimod-treated ( $2 \mathrm{~h}$ and $5 \mathrm{~h}$ ) versus vehicle-treated mice $(n=3-5$ mice /group). Flow cytometry was used to identify $\mathrm{N} \phi\left(C D 45^{+} \mathrm{CD} 11 \mathrm{~b}^{+} \mathrm{Ly}-6 \mathrm{C}^{+} \mathrm{Ly}-6 \mathrm{G}^{\mathrm{hi}}\right)$. B Absolute number of endogenous and adoptively transferred $\mathrm{N} \phi$ in the $\mathrm{BM}$, liver, and lungs $2 \mathrm{~h}$ post-treatment with vehicle or entolimod ( $n=6-8 \mathrm{mice} / \mathrm{group}$ ). Adoptive transfers were done by i.v. injection of GFPexpressing BM immediately before treatment. Endogenous versus transferred N $\phi$ were distinguished by flow cytometry for GFP among the total $\mathrm{N} \phi$ population $\left(\mathrm{CD} 45^{+} \mathrm{CD} 11 \mathrm{~b}^{+} \mathrm{Ly}-6 \mathrm{C}^{+} \mathrm{Ly}-6 \mathrm{G}^{\mathrm{hi}}\right)$. C Absolute number (left) and composition (right) of $\mathrm{N} \phi$ populations in the bone marrow at the indicated time points post-treatment by flow cytometry as defined by: pre-N $\phi$ (Lineage ${ }^{-} \mathrm{C}^{-\mathrm{kit}^{\mathrm{int}}} \mathrm{CD}^{\mathrm{C}} 15^{-} \mathrm{CD} 11 \mathrm{~b}^{+} \mathrm{Gr}-1^{+} \mathrm{CXCR4^{+ }}$ ),

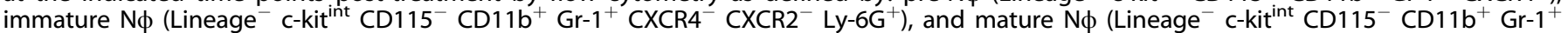
$\mathrm{CXCR4}^{-} \mathrm{CXCR2}^{+} \mathrm{Ly}^{-6 \mathrm{G}^{+}}$) where lineage was defined as CD3 ${ }^{-}$and B220 ${ }^{-}$( $n=3-9$ mice/group). D Flow cytometry-based staining for TLR5

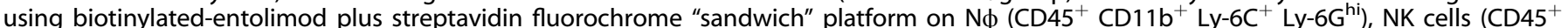

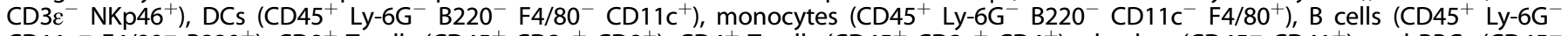
CD11 $\left.\mathrm{c}^{-} \mathrm{F} 4 / 80^{-} \mathrm{B}^{2} 20^{+}\right), \mathrm{CD} 8^{+}$T cells $\left(\mathrm{CD} 45^{+} \mathrm{CD} 3 \varepsilon^{+} \mathrm{CD}^{+}\right), \mathrm{CD}^{+}$T cells $\left(\mathrm{CD} 45^{+} \mathrm{CD} 3 \varepsilon^{+} \mathrm{CD}^{+}\right)$, platelets $\left(\mathrm{CD} 45^{-} \mathrm{CD}^{+} 1^{+}\right)$, and RBCs $\left(\mathrm{CD} 45^{-}\right.$ Ter $119^{+}$) in the blood of BALB/c and $T / r 5^{-1-}$ mice. Error bars represent mean \pm SEM. ${ }^{*} P<0.04 ; P$-values were determined by Student's $t$-test. 
A

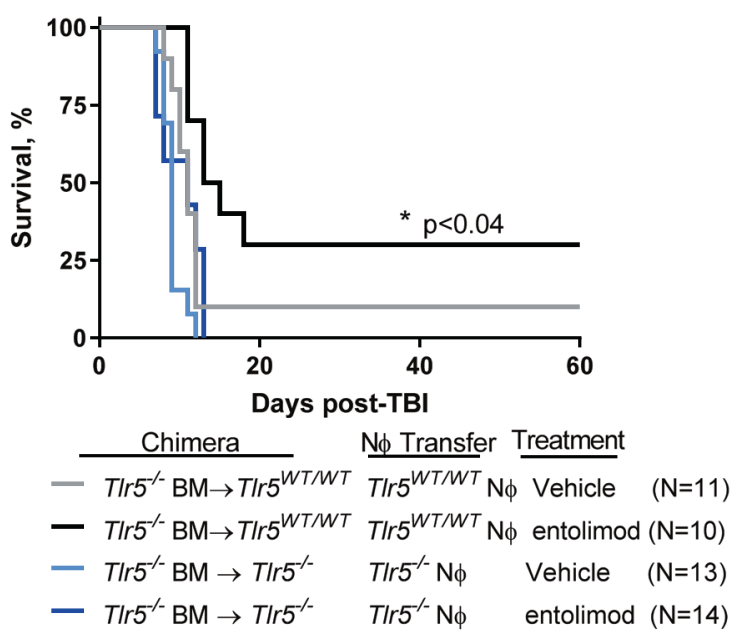

B

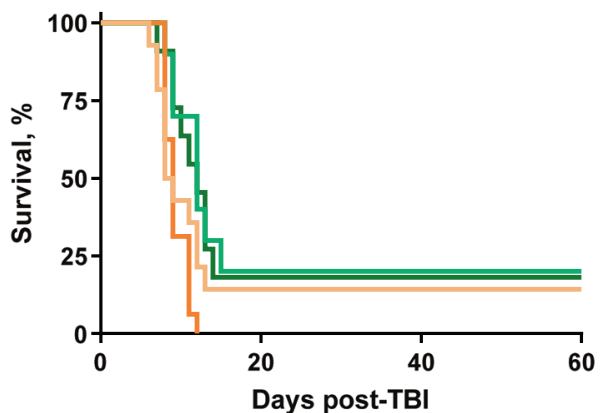

C

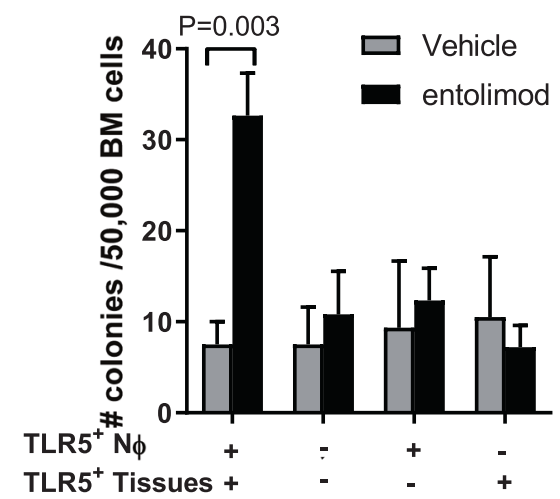

Fig. 3 TLR5 activation on $\mathrm{N} \phi$ and non-hematopoietic cells cooperate to mitigate radiation damage. $T / r 5^{-1-}$ bone marrow chimeric mice received an adoptive transfer of either Tlr $5^{W T M T}$ or Tlr5 ${ }^{-/-}$ $\mathrm{N} \phi$ (10 million /mouse) followed immediately by vehicle or entolimod $24 \mathrm{~h}$ post-TBI. A, B Survival was measured by Kaplan-Meier curves. $P$ values were determined by Log-rank test; $n=10-16$ mice/group. C Measurement of total HPPs by MethoCult in BM on day 7 posttreatment using the same experimental setup as A. Error bars represent mean $\pm \mathrm{SEM}$; $P$-values were determined by Student's $t$-test; $n=4-7$ mice/group. In all instances, $\mathrm{N} \phi$ purity was routinely $>98 \%$.

$\mathrm{BM} \rightarrow \mathrm{Tl} r 5^{-/-}$chimeras); (iii) only N $\phi$ expressed TLR5 (wild-type $\mathrm{N} \phi$ into $\mathrm{Tlr}^{-1-} \mathrm{BM} \rightarrow \mathrm{Tlr}^{-1-}$ chimeras); and (iv) only nonhematopoietic cells expressed TLR5 (T/r5 $5^{-/} \mathrm{N} \phi$ into T/r5 $5^{-/-}$ $\mathrm{BM} \rightarrow$ wild-type chimeras). Entolimod significantly improved overall survival when both cell populations expressed TLR5 (black vs. gray curves, Fig. 3A). The radiomitigative activity of entolimod was abrogated when both populations were TLR5-deficient (dark blue vs. light blue curves, Fig. $3 \mathrm{~A}$ ), which is further substantiated by the inability of entolimod to improve survival and stimulate HPPs recovery in the BM of Tlr5 $5^{-1-}$ mice post-TBI (Supplementary Fig. S4). Entolimod was unable to mitigate radiation damage when either $\mathrm{N} \phi$ (dark orange vs. light orange) or non-hematopoietic cells (dark green vs. light green) expressed TLR5 (Fig. 3B). Consistent with these findings, accelerated recovery of HPPs in the BM was only observed when both $\mathrm{N} \phi$ and non-hematopoietic cells express TLR5 (Fig. 3C). Thus, these data show that stimulating TLR5 on both N $\phi$ and non-hematopoietic cells (i.e., hepatocytes) is required for mitigating lethal ARS.

\section{Release of MMP-9 by entolimod-stimulated N $\phi$ mitigates lethal radiation damage}

Our prior work showing that G-CSF and IL- 6 contribute to the radiomitigative activity of entolimod [14] led us to determine whether $N \phi$ mitigate ARS post-entolimod treatment by mediating the release of these cytokines. Depletion of $N \phi$ with a-Ly6G prior to entolimod treatment did not diminish the expression of either G-CSF or IL-6 in serum (Supplementary Fig. S5A). Moreover, entolimod-stimulated comparable serum levels of both cytokines in bone marrow chimeric mice expressing TLR5 in either nonhematopoietic cells or both $\mathrm{N} \phi$ and non-hematopoietic cells (Supplementary Fig. S5B). Thus, the critical impact of $\mathrm{N} \phi$ in the radiomitigative activities of entolimod is not mediated by the release of G-CSF and IL-6.

Given that $\mathrm{N} \phi$ express functional TLR5 and that the underlying effects of TLR5 agonists have been associated with NF-KBdependent transcriptional events [19], we hypothesized that changes in the transcriptional profile of $N \phi$ post-entolimod mitigate ARS. However, RNA sequencing data analysis showed that ex vivo stimulation of $\mathrm{N} \phi$ with entolimod caused changes in transcriptional profiles that were substantially weaker-both in the numbers of responsive genes and scales of changes-as compared with that of liver cells following in vivo treatment with entolimod (Supplementary Fig. S6). This observation suggests that mitigation of lethal ARS by $\mathrm{N} \phi$ post-entolimod involves a transcriptional-independent mechanism.

To determine potential factors released by entolimodstimulated $N \phi$ that contribute to the mitigation of ARS, we analyzed serum from mice that retained (rat lgG) or lacked (aLy6G) N $\phi$ using a protein microarray that simultaneously measures 111 soluble factors. We identified MMP-9 as the single factor reduced in the serum of $\mathrm{N} \phi$-depleted mice when compared to control-treated serum (Fig. 4A). Consistent with this finding, MMP9 was also the only factor released by $N \phi$ into supernatants after ex vivo stimulation with entolimod (Fig. 4B). In support of the protein microarray data, $\mathrm{N} \phi$ depletion prior to entolimod treatment abrogated the increased levels of MMP-9 in serum as measured by ELISA (Fig. 4C). Moreover, N $\phi$ released MMP-9 in supernatants following ex vivo stimulation in a TLR5-dependent manner (Fig. 4D). These data show that entolimod stimulates $N \phi$ to release MMP-9 and are consistent with prior observations that $\mathrm{N} \phi$ are the main cellular source of MMP-9 [31-35].

Because the release of MMP-9 by $\mathrm{N} \phi$ supports hematopoiesis $[36,37]$, we hypothesized that entolimod mitigates ARS through $\mathrm{N} \phi-$ dependent release of MMP-9. We first measured whether the radiomitigative effects of rMMP-9 are linked to HPPs recovery in BM as measured by MethoCult. In fact, rMMP-9 administration $24 \mathrm{~h}$ postTBI accelerated the recovery of HPPs in a dose-dependent manner with $10 \mu \mathrm{g} / \mathrm{kg}$ rMMP-9 showing optimal recovery similarly to entolimod (Fig. 5A). Moreover, significantly improved survival was observed following rMMP-9 administration and was strikingly similar to improved survival observed with entolimod (Fig. 5B). These data underscore that both entolimod and rMMP-9 mitigate lethal ARS. 
A
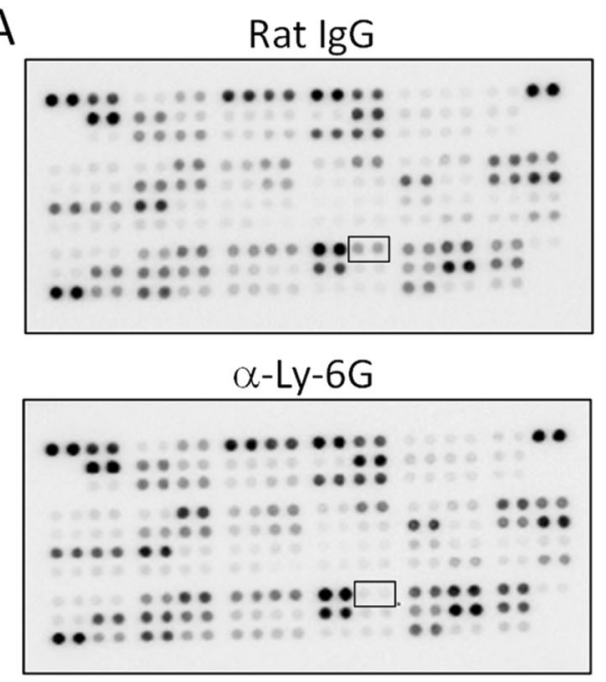

C

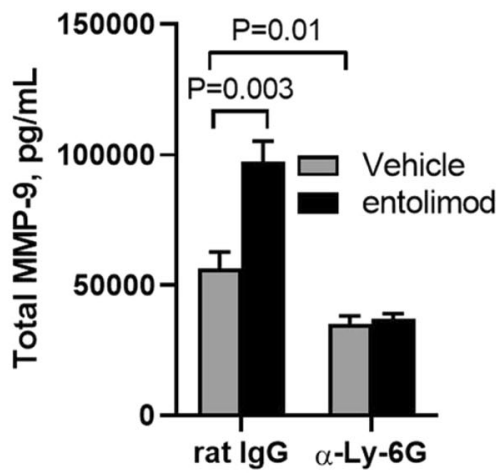

B Vehicle
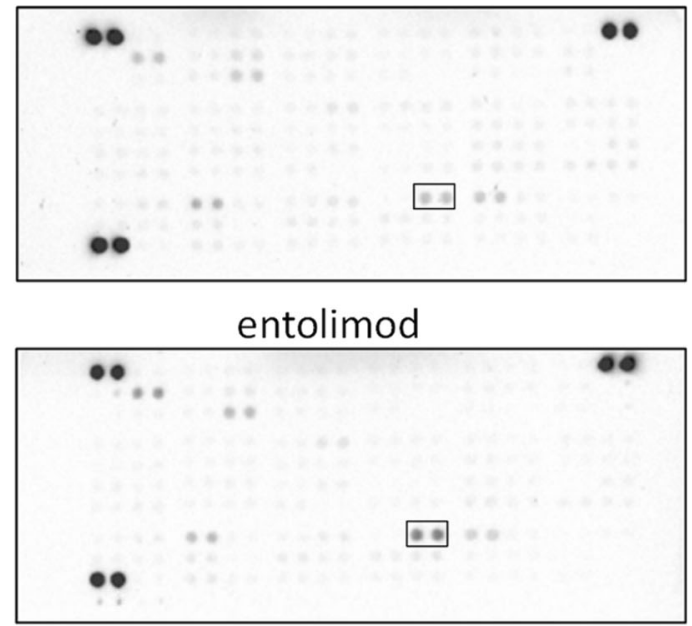

D

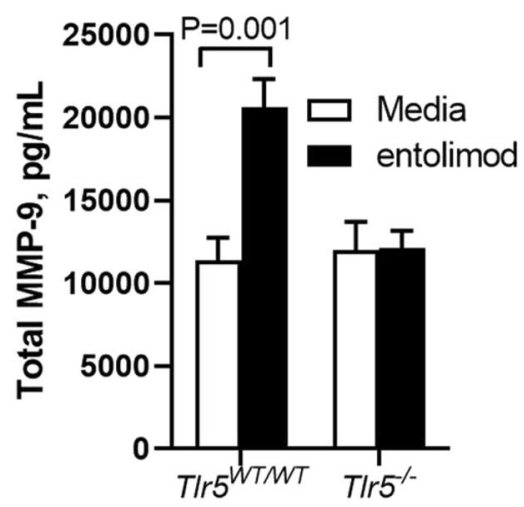

Fig. 4 Entolimod stimulates $\mathbf{N} \phi$ to release MMP-9. Protein microarray analysis of $\mathbf{A}$ mouse serum using R\&D Systems Proteome Profiler Mouse $\mathrm{XL}$ Cytokine Array in the presence (rat IgG) and absence ( $\alpha-\mathrm{Ly}-6 \mathrm{G})$ of $\mathrm{N} \phi 24 \mathrm{~h}$ post-TBI and B N $\phi$ isolated from BM that were ex vivo treated with vehicle or entolimod for $30 \mathrm{~min}$. Measurement by ELISA of MMP-9 in C serum from mice ( $n=5 / \mathrm{group})$ in the presence (rat IgG) and absence $(\alpha-\mathrm{Ly}-6 \mathrm{G})$ of $\mathrm{N} \phi 2 \mathrm{~h}$ post-treatment with vehicle or entolimod (TBI was delivered $24 \mathrm{~h}$ prior to vehicle or entolimod) and $\mathbf{D}$ supernatants from TIr5 $5^{W T / W T}$ and TIr5 ${ }^{-1-} \mathrm{N} \phi$ isolated from BM ( $n=6$ mice/group) and ex vivo treated with vehicle or entolimod for $30 \mathrm{~min}$.

Lastly, we sought to causally link the release of MMP-9 by entolimod-stimulated $\mathrm{N} \phi$ to mitigation of ARS. To do this, mice that retained (rat IgG) or lacked (a-Ly6G) N $\phi$ were stratified into four treatment cohorts consisting of vehicle, entolimod, rMMP-9, and rMMP-9 plus entolimod (Fig. 5C). In the presence of $\mathrm{N} \phi$, both entolimod and rMMP-9 increased the number of BM HPPs with a modest but significant increase when both rMMP-9 and entolimod were administered. In $\mathrm{N} \phi$-deficient mice, HPPs only recovered to similar levels observed in N $\phi$ sufficient mice when both rMMP-9 and entolimod were administered. Collectively, these data show that both the release of MMP-9 by $N \phi$ and the inflammatory response (e.g., G-CSF) induced by TLR5 stimulation mitigate ARS.

\section{DISCUSSION}

The remarkable efficacy of TLR5 agonists as a radiomitigator has been recognized for many years, but a lack of mechanistic knowledge regarding which components of this multifunctional pathway rescue lethally irradiated organisms has significantly impeded the clinical development of TLR5 agonists as a radiation countermeasure following accidental exposure to ionizing radiation. Uncovering this mechanism is especially important provided the safety concerns of using bacterial protein (flagellin) derivatives, which are known to induce an IL-6-driven inflammatory response. Here, we provide evidence supporting the key role for the release of MMP-9 by TLR5-stimulated $\mathrm{N} \phi$ as an essential mediator of radiomitigation.

We began this study by uncovering key differences in how the TLR5 agonist entolimod protects and mitigates radiation damage, which is reflected by the state of radiosensitive organs such as the HPS when a TLR5 agonist is administered. HPPs are intact prior to radiation thereby conferring protection from death by a series of pro-survival effects initiated by TLR5-mediated activation of NF-KB response including suppression of apoptosis (e.g., $\mathrm{BCl}-2$ ) and induction of natural endogenous antioxidants (e.g., superoxide dismutase) and anti-microbial factors (e.g., hepcidin) [12, 13, 19]. In stark contrast, post-irradiation treatment with radiomitigators requires rescuing an already damaged HPS that undergoes apoptotic death within the first $8 \mathrm{~h}$ post-TBI [38].

The previously identified mechanisms underlying the effects of TLR5 agonists have been associated with NF-KB-dependent transcriptional events [19] and prompted us to understand the transcriptome changes that occur in $\mathrm{N} \phi$ post-entolimod. Although neutrophils express TLR5, we found minimal transcriptional changes in similar pathways that are markedly increased in the liver post-entolimod. Rather, $\mathrm{N} \phi$ respond to entolimod by rapid and pronounced changes in proteins at the plasma membrane ( $\mathrm{L}-$ selectin downregulation and $\mathrm{CD} 11 \mathrm{~b}$ upregulation) to support 
A
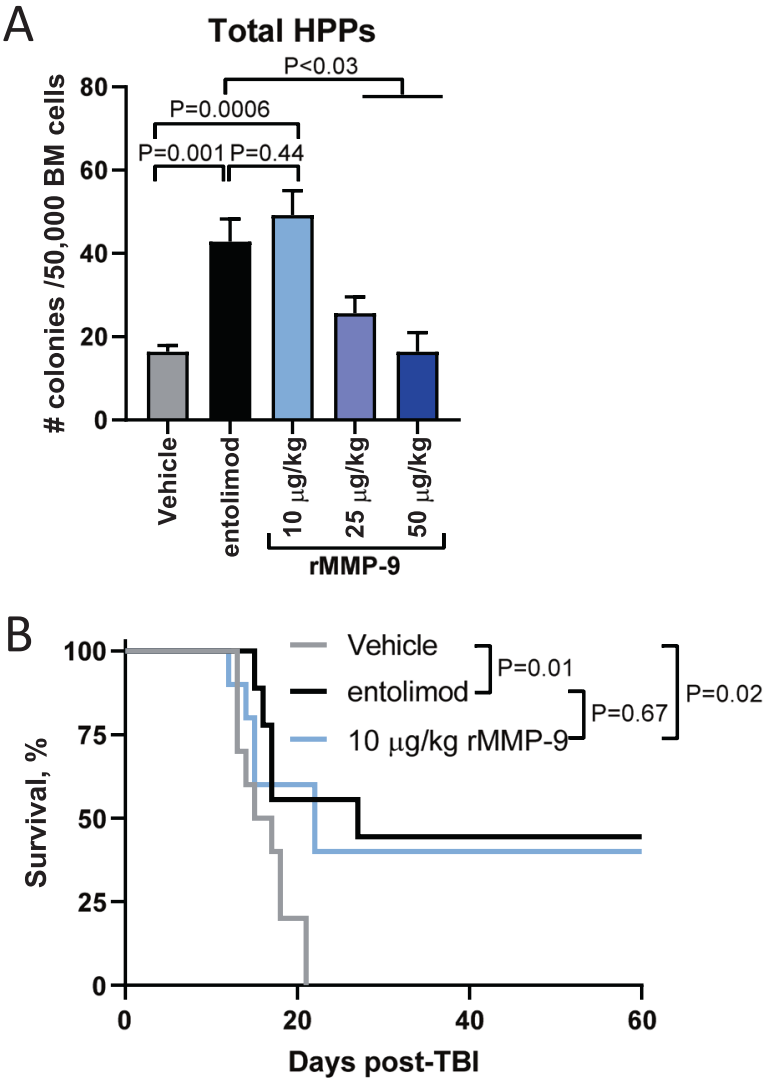

C

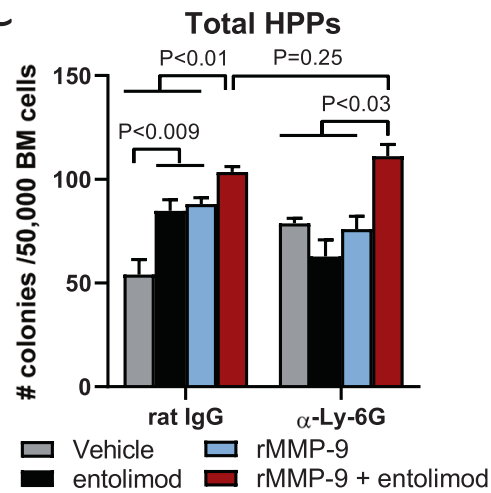

Fig. 5 Release of MMP-9 by $\mathrm{N} \phi$ post-entolimod mitigates lethal radiation damage to hematopoiesis. A BALB/c mice ( $n=5 /$ group) were given $5 \mathrm{~Gy}$ TBI followed $24 \mathrm{~h}$ later by treatment with vehicle, entolimod, or the indicated doses of recombinant pro-MMP-9 (rMMP-9). Measurement of total HPPs in BM by MethoCult was done on day 3 post-treatment. B Survival by Kaplan-Meier curve in BALB/ c mice treated with vehicle, entolimod, or $10 \mu \mathrm{g} / \mathrm{kg}$ rMMP-9 $24 \mathrm{~h}$ post 7.5 Gy TBI ( $n=9-10$ mice /group). $P$-values were determined by the Log-rank test. C BALB/c mice ( $n=5$ /group) were given 5 Gy TBI followed $6 \mathrm{~h}$ later by rat lgG or $\alpha$-Ly-6G. Twenty-four hours later mice were treated with vehicle, entolimod, rMMP-9 $(10 \mu \mathrm{g} / \mathrm{kg})$, or rMMP-9 plus entolimod. Measurement of total HPPs in BM by MethoCult was done on day 3 post-treatment. For $\mathbf{A}$ and $\mathbf{C}$ error bars represent mean $\pm \mathrm{SEM}$; $P$-values were determined by Student's $t$-test.

extravasation across endothelial walls and accumulation in tissues as is observed with other cell-surface TLRs [26-29]. Moreover, the release of MMP-9 by $\mathrm{N} \phi$ is among the most striking microenvironment-changing factor post-TLR5 stimulation, which is post-transcriptionally released from tertiary granules following stimulation with a variety of mediators [31-35]. Since the release of MMP-9 by $\mathrm{N} \phi$ is linked to stimulating hematopoiesis [21], we focused on MMP-9 as a potential contributor to $\mathrm{N} \phi$-mediated radiomitigative effects of TLR5 agonists.

MMP-9 is a metalloproteinase that is well-recognized for promoting tumor invasion and metastasis and thus is studied as a therapeutic target in cancer [reviewed in [39]]. Even though a series of reports demonstrated the involvement of MMP-9 in "opening" HP niches in order to promote hematopoietic recovery $[36,40]$, to the best of our knowledge considering recombinant MMP-9 (rMMP-9) as a pharmacologically feasible stimulator of blood regeneration following induction of systemic genotoxic stress (SGS) by radiation exposure has not been considered. Our data show that administering rMMP-9 has radiomitigative capabilities to strikingly similar levels as entolimod in terms of survival and accelerating the recovery of the number of BM HPPs. Moreover, rMMP-9 plus entolimod administration restores the radiomitigative capabilities of entolimod in the absence of $N \phi$, demonstrating a causal link between TLR5 agonist-stimulated $N \phi$ and MMP-9 as a radiomitigator. These findings are supported by the known ability of MMP-9 to cleave several cytokines and/or their receptors, a process that can activate cytokines playing a role in cellular remodeling [41], HSC mobilization to the circulation $[37,40,42,43]$, and HSC homing to the BM [44].

These collective findings delineate an attractive possibility of considering rMMP-9 as a radiomitigator for clinical applications involving SGS. In stark contrast to the immunogenic inflammatory response induced by entolimod that has limited its clinical development, MMP-9 is a natural endogenous human factor with no detected inflammatory activities and thus has clear advantages over entolimod as a radiomitigator. It is highly unlikely that the association of MMP-9 with tumor invasion and metastasis would have any relevance to its use as a radiomitigator since the protumor effects are associated with chronic production [45] while the post-administration effects of MMP-9 as a radiomitigator would be considered shorter lasting.

The release of MMP- 9 by N $\phi$ plays a pivotal role in TLR5 agonistmediated regeneration of the HPS in response to radiationinduced damage (Fig. 6). However, MMP-9 is unlikely the sole driver of radiomitigation based on the high concentration of G-CSF and IL- 6 in the circulation post-entolimod that stimulates HPS regeneration [14]. Based on prior work [21], MMP-9 likely augments the release of G-CSF to increase the number of HPPs in the BM. Currently, G-CSF is broadly used as an accelerator of hematopoietic restoration following myeloablative chemotherapy [46] and the G-CSF-based drugs Neupogen and Neulasta have been stockpiled as radiomitigators for emergency use [47]. Although IL-6 was shown to stimulate megakaryocytic precursor [48], its potent pyrogenic activity [49] has a controversial role as a likely mediator of flu-like syndrome in entolimod applications. Therefore, it would be important to test the efficacy of a combination of rMMP-9 and G-CSF as a potential new radiomitigator lacking the drawbacks and limitations of TLR5 agonists for mass casualty situations.

\section{MATERIALS AND METHODS}

\section{Mice}

Pathogen-free inbred BALB/C mice were obtained from The Jackson Laboratories or from our colony maintained at Roswell Park. BALB/cT/r5 $5^{-1-}$ mice obtained from Dr. Shibata [24] and C57BL/6-GFP breeders [C57BL/6-Tg(UBC-GFP)30Scha/J] purchased from The Jackson Laboratories were all bred and maintained by Roswell Park Laboratory Animal Shared Resource (LASR). All mice were housed in microisolator cages in a laminar flow unit under ambient light. The Roswell Park Institutional Animal Care and Use Committee (IACUC) approved all procedures carried out in this study. Adult female mice between the ages of 11 and 12 weeks were assigned randomly to groups; group sizes were selected based on prior experience. No animals were excluded from further analysis in the reported studies. 

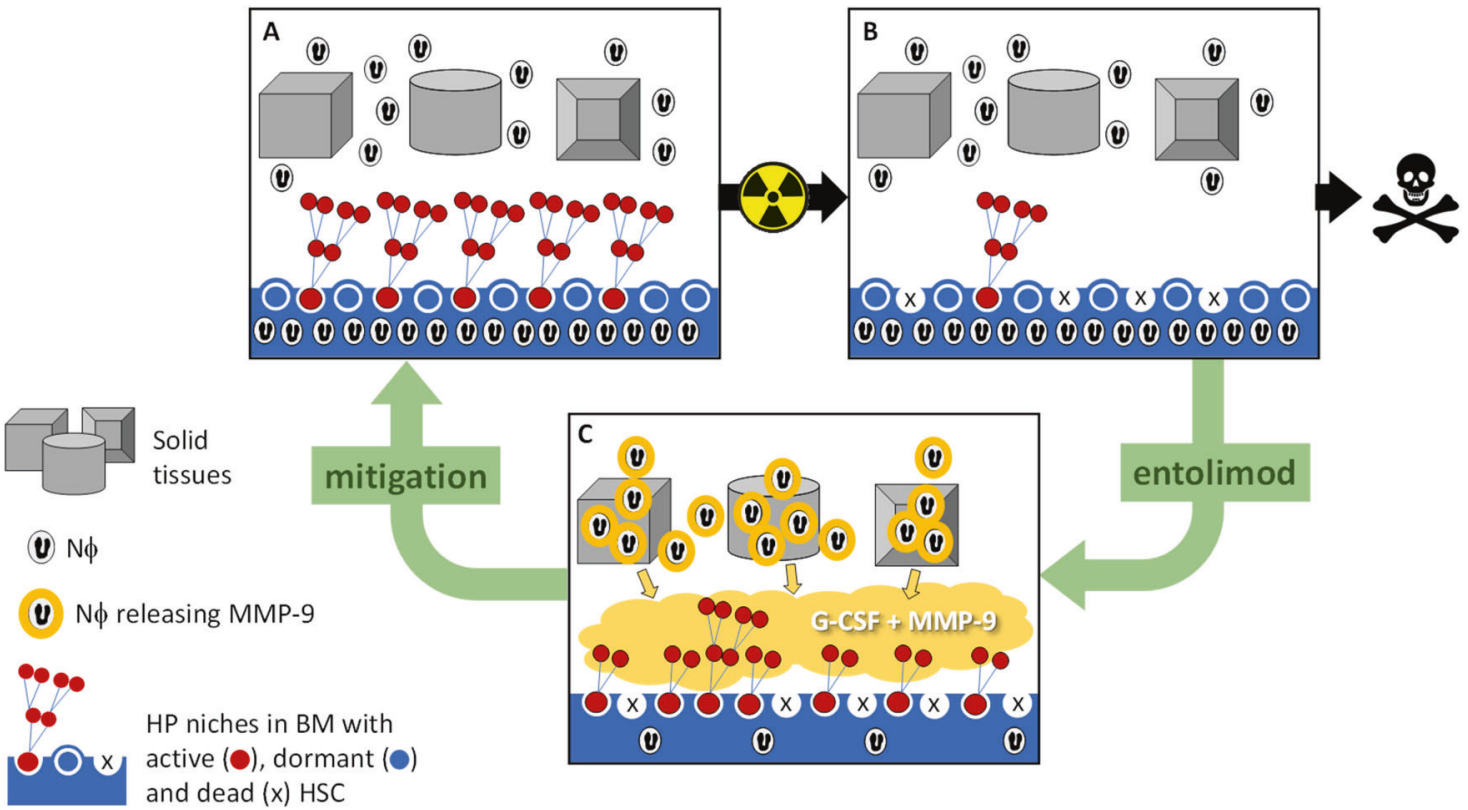

Fig. 6 Proposed mechanism by which entolimod mitigates lethal ARS to hematopoiesis. Following lethal radiation damage, entolimod stimulates $\mathrm{N} \phi$ to release MMP-9 which, in cooperation with G-CSF, accelerates the recovery of hematopoiesis.

\section{Generation of $\mathrm{Tlr5} \mathrm{5}^{-/-}$bone marrow chimeric mice}

$\mathrm{BALB} / \mathrm{C}$ and $T / \mathrm{r} 5^{-/-}$mice received a fractionated dose ( $3.75 \mathrm{~Gy} 3 \mathrm{~h}$ apart) of TBI using a 4000 Ci Cesium-137 source (J.L. Shepherd and Associates, San Fernando, CA) on a rotating platform to ensure even dose delivery to all tissues. Mice received syngeneic bone marrow transplantation by intravenous (i.v.) injection $24 \mathrm{~h}$ later. Mice rested for at least 9 weeks prior to enrollment into studies.

\section{Reagents}

The TLR5 agonist entolimod (CBLB502) is a CGMP-manufactured drug product that was obtained from Cleveland BioLabs, Inc. [12]. We purchased mouse MethoCult GF and MethoCult without cytokines from STEMCELL Technologies, recombinant mouse G-CSF from Peprotech, rat IgG2a, $K$ (clone $2 A 3$ ) and a-Ly-6G (clone 1A8) from BioXcell, Proteome Profiler Mouse XL Cytokine Array from R\&D Systems, Duoset ELISA kits from R\&D Systems, and recombinant mouse MMP-9 from BioLegend. All reagents were handled according to the manufacturer's instructions.

\section{Radioprotection and radiomitigation studies}

Mice received 7.5 Gy TBI similarly as described above for all studies except for non-survival radiomitigation studies in which mice received 5 Gy TBI. Mice received vehicle (PBS) or entolimod $(1 \mu \mathrm{g})$ s.c. $30 \mathrm{~min}$ pre-TBI for radioprotection studies $[12,15,19]$ or $24 \mathrm{~h}$ post-TBI for radiomitigation studies $[13,14]$.

\section{$\mathbf{N} \phi$ depletion and isolation}

To effectively deplete $N \phi$, mice were intraperitoneally (i.p.) administered mAbs against Ly6G ( $100 \mu \mathrm{g} /$ mouse) $18 \mathrm{~h}$ prior to vehicle or entolimod administration. Isotype-matched controls (rat $\operatorname{lgG} 2 \mathrm{a}, \mathrm{k}$ ) were given at the same dose and regimen as the depletion mAbs. $\mathrm{N} \phi$ isolation and transfer were achieved by magnetic bead isolation from the bone marrow of naïve mice according to the manufacturer's protocol using the ultrapure Ly6G microbead kit (Miltenyi Biotec). Purity was routinely greater than $98 \% \mathrm{~N} \phi$ were transferred via i.v. injection immediately before vehicle or entolimod administration.

\section{FACS staining and analysis}

Single-cell suspensions of tissues were generated as outlined (Supplementary Table 1). Erythrocytes were lysed using a solution of ammonium chloride for $5 \mathrm{~min}$ at room temperature except for when Ter-119 was used in Panel 1. Live cells were counted by trypan blue exclusion, resuspended in phosphate azide buffer (PAB), and stained on ice for $10 \mathrm{~min}$ with
TruStain $\mathrm{fC} \mathrm{X}^{\mathrm{TM}}$ (clone 93, BioLegend for Panels 1 and 2) or rat serum (for Panel 3) followed by a cocktail of mAbs or isotype-matched controls for 15 min (Supplementary Table 2). We biotinylated entolimod with the EZLink $^{\text {TM }}$ Sulfo-NHS-LC-Biotinylation Kit (ThermoFisher). After staining, cells were washed once with $P A B$ and fixed in $2 \%$ ultrapure formalin (Polysciences). Data was acquired within $48 \mathrm{~h}$ of fixation on a LSRII Fortessa instrument (Becton Dickinson), stored in Listmode format, and analyzed using WinList software (Verity House Software, Topsham ME).

\section{Enumeration of HPPs}

Femurs and tibias were crushed with a sterilized mortar and pestle to generate a single cell suspension followed by erythrocyte lysis. Total live BM cells were counted by trypan blue exclusion and an equal number was plated in MethoCult GF (supports the growth of HPPs) or MethoCult with the addition of $50 \mathrm{ng} / \mathrm{mL} \mathrm{G-CSF}$ (supports the growth of granulocyte/ macrophage $(\mathrm{G} / \mathrm{M})$ progenitors [19]). The number of colonies were enumerated under a microscope on day 7 after plating and normalized to 50,000 total live BM cells for radiomitigation studies.

\section{Measurement of cytokine response}

Serum was collected after centrifugation of naturally clotted whole blood for at least $1 \mathrm{~h}$ at room temperature. Serum and supernatants collected from ex vivo stimulated N\$ were subjected to G-CSF, IL-6, and total MMP-9 ELISAs or R\&D Systems Proteome Profiler Mouse XL Cytokine Array.

\section{Statistical evaluation}

Experiments were not blinded and were repeated at least once. Data are presented as mean \pm SEM of biological replicates. Differences between groups within experiments were analyzed in GraphPad Prism 9 software using unpaired Student's $t$-test. Animal survival Kaplan-Meier curves were compared using the Log-rank test. A similar variance was observed between the groups that were statistically compared. Statistical significance between groups was defined as $P<0.05$.

\section{DATA AVAILABILITY}

The authors declare that all data supporting this study are available within the article and its Supplementary Information file, may be obtained from the corresponding author upon reasonable request, or in the case of our RNA-seq experiment comparing gene expression in mouse $\mathrm{N} \phi$ or livers treated with vehicle or entolimod are available in NCBI's Gene Expression Omnibus (GEO) database under accession number GSE179808 or GSE163748, respectively. 


\section{REFERENCES}

1. Singh VK, Garcia M, Wise SY, Seed TM. Medical countermeasures for unwanted CBRN exposures: Part I chemical and biological threats with review of recent countermeasure patents. Expert Opin Ther Pat. 2016;26:1431-47.

2. Weiss JF, Landauer MR. Radioprotection by antioxidants. Ann N Y Acad Sci. 2000;899:44-60.

3. Komarova EA, Chernov MV, Franks R, Wang K, Armin G, Zelnick CR, et al. Transgenic mice with p53-responsive lacZ: p53 activity varies dramatically during normal development and determines radiation and drug sensitivity in vivo. EMBO J. 1997;16:1391-400.

4. Hendry JH, Adeeko A, Potten CS, Morris ID. P53 deficiency produces fewer regenerating spermatogenic tubules after irradiation. Int J Radiat Biol. 1996;70:677-82.

5. Urbaschek R, Mannel DN, Urbaschek B. Tumor necrosis factor induced stimulation of granulopoiesis and radioprotection. Lymphokine Res. 1987;6:179-86.

6. Basile LA, Ellefson D, Gluzman-Poltorak Z, Junes-Gill K, Mar V, Mendonca S, et al. HemaMax, a recombinant human interleukin-12, is a potent mitigator of acute radiation injury in mice and non-human primates. PloS ONE. 2012;7: e30434.

7. Webster GA, Perkins ND. Transcriptional cross talk between NF-kappaB and p53. Mol Cell Biol. 1999;19:3485-95.

8. Singh VK, Newman VL, Berg AN, MacVittie TJ. Animal models for acute radiation syndrome drug discovery. Expert Opin Drug Discov. 2015;10:497-517.

9. Waselenko JK, MacVittie TJ, Blakely WF, Pesik N, Wiley AL, Dickerson WE, et al. Medical management of the acute radiation syndrome: recommendations of the Strategic National Stockpile Radiation Working Group. Ann Intern Med. 2004;140:1037-51.

10. Dainiak N, Gent RN, Carr Z, Schneider R, Bader J, Buglova E, et al. First global consensus for evidence-based management of the hematopoietic syndrome resulting from exposure to ionizing radiation. Disaster Med Public Health Prep. 2011;5:202-12.

11. FDA approves radiation medical countermeasure [Internet]. Place unknown: U.S. Food \& Drug Administration; 2015. FDA approves Neupogen for treatment of patients with radiation-induced myelosuppression following a radiological/ nuclear incident; 2019 April 30 [cited 2021 April 5]; Available from: https://www. fda.gov/emergency-preparedness-and-response/about-mcmi/fda-approvesradiation-medical-countermeasure.

12. Burdelya LG, Krivokrysenko VI, Tallant TC, Strom E, Gleiberman AS, Gupta D, et al. An agonist of toll-like receptor 5 has radioprotective activity in mouse and primate models. Science. 2008;320:226-30.

13. Krivokrysenko VI, Toshkov IA, Gleiberman AS, Krasnov P, Shyshynova I, Bespalov I, et al. The toll-like receptor 5 agonist entolimod mitigates lethal acute radiation syndrome in non-human primates. PLoS ONE. 2015;10:e0135388.

14. Krivokrysenko VI, Shakhov AN, Singh VK, Bone F, Kononov Y, Shyshynova I, et al. Identification of granulocyte colony-stimulating factor and interleukin- 6 as candidate biomarkers of CBLB502 efficacy as a medical radiation countermeasure. $J$ Pharm Exp Ther. 2012:343:497-508.

15. Burdelya LG, Gleiberman AS, Toshkov I, Aygun-Sunar S, Bapardekar $M$ Manderscheid-Kern $\mathrm{P}$, et al. Toll-like receptor 5 agonist protects mice from dermatitis and oral mucositis caused by local radiation: implications for head-andneck cancer radiotherapy. Int J Radiat Oncol Biol Phys. 2012;83:228-34.

16. Toshkov IA, Gleiberman AS, Mett VL, Hutson AD, Singh AK, Gudkov AV, et al. Mitigation of radiation-induced epithelial damage by the TLR5 agonist entolimod in a mouse model of fractionated head and neck irradiation. Radiat Res. 2017;187:570-80.

17. Kojouharov BM, Brackett CM, Veith JM, Johnson CP, Gitlin II, Toshkov IA, et al. Tolllike receptor-5 agonist entolimod broadens the therapeutic window of 5 -fluorouracil by reducing its toxicity to normal tissues in mice. Oncotarget. 2014;5:802-14.

18. Fukuzawa N, Petro M, Baldwin WM 3rd, Gudkov AV, Fairchild RL. A TLR5 agonist inhibits acute renal ischemic failure. J Immunol. 2011;187:3831-9.

19. Burdelya LG, Brackett CM, Kojouharov B, Gitlin II, Leonova KI, Gleiberman AS, et al Central role of liver in anticancer and radioprotective activities of toll-like receptor 5 agonist. Proc Natl Acad Sci USA. 2013;110:E1857-66.

20. Haderski GJ, Kandar BM, Brackett CM, Toshkov IM, Johnson CP, Paszkiewicz GM, et al. TLR5 agonist entolimod reduces the adverse toxicity of TNF while preserving its antitumor effects. PLoS ONE. 2020;15:e0227940.

21. Pelus LM, Bian H, King AG, Fukuda S. Neutrophil-derived MMP-9 mediates synergistic mobilization of hematopoietic stem and progenitor cells by the combination of G-CSF and the chemokines GRObeta/CXCL2 and GRObetaT/ CXCL2delta4. Blood. 2004;103:110-9.

22. Daley JM, Thomay AA, Connolly MD, Reichner JS, Albina JE. Use of Ly6G-specific monoclonal antibody to deplete neutrophils in mice. J Leukoc Biol. 2008;83:64-70.
23. Evrard M, Kwok I, Chong SZ, Teng K, Becht E, Chen J, et al. Developmental analysis of bone marrow neutrophils reveals populations specialized in expansion, trafficking, and effector functions. Immunity. 2018;48:364-79.

24. Shibata T, Takemura N, Motoi Y, Goto Y, Karuppuchamy T, Izawa K, et al. PRAT4Adependent expression of cell surface TLR5 on neutrophils, classical monocytes and dendritic cells. Int Immunol. 2012;24:613-23.

25. Medzhitov R, Preston-Hurlburt $P$, Kopp E, Stadlen A, Chen C, Ghosh $S$, et al MyD88 is an adaptor protein in the hToll/IL-1 receptor family signaling pathways. Mol Cell. 1998;2:253-8.

26. Kuijpers TW, Hakkert BC, Hoogerwerf M, Leeuwenberg JF, Roos D. Role of endothelial leukocyte adhesion molecule-1 and platelet-activating factor in neutrophil adherence to IL-1-prestimulated endothelial cells. Endothelial leukocyte adhesion molecule-1-mediated CD18 activation. J Immunol. 1991;147:1369-76.

27. Andonegui G, Bonder CS, Green F, Mullaly SC, Zbytnuik L, Raharjo E, et al. Endothelium-derived toll-like receptor-4 is the key molecule in LPS-induced neutrophil sequestration into lungs. J Clin Investig. 2003;111:1011-20.

28. Simon SI, Burns AR, Taylor AD, Gopalan PK, Lynam EB, Sklar LA, et al. L-selectin (CD62L) cross-linking signals neutrophil adhesive functions via the Mac-1 (CD11b/CD18) beta 2-integrin. J Immunol. 1995;155:1502-14.

29. Walcheck B, Kahn J, Fisher JM, Wang BB, Fisk RS, Payan DG, et al. Neutrophil rolling altered by inhibition of L-selectin shedding in vitro. Nature. 1996;380:720-3.

30. Hernandez A, Bohannon JK, Luan L, Fensterheim BA, Guo Y, Patil NK, et al. The role of MyD88- and TRIF-dependent signaling in monophosphoryl lipid A-induced expansion and recruitment of innate immunocytes. J Leukoc Biol. 2016;100:1311-22.

31. Borregaard N, Cowland JB. Granules of the human neutrophilic polymorphonuclear leukocyte. Blood. 1997;89:3503-21.

32. Borregaard N, Theilgaard-Monch K, Sorensen OE, Cowland JB. Regulation of human neutrophil granule protein expression. Curr Opin Hematol. 2001;8:23-7.

33. Opdenakker G, Van den Steen PE, Dubois B, Nelissen I, Van Coillie E, Masure S, et al. Gelatinase B functions as regulator and effector in leukocyte biology. J Leukoc Biol. 2001;69:851-9.

34. Pugin J, Widmer MC, Kossodo S, Liang CM, Preas, Suffredini AF. Human neutrophils secrete gelatinase $B$ in vitro and in vivo in response to endotoxin and proinflammatory mediators. Am J Respir Cell Mol Biol. 1999;20:458-64.

35. Chakrabarti S, Zee JM, Patel KD. Regulation of matrix metalloproteinase-9 (MMP9) in TNF-stimulated neutrophils: novel pathways for tertiary granule release. J Leukoc Biol. 2006;79:214-22.

36. Pruijt JF, Fibbe WE, Laterveer L, Pieters RA, Lindley IJ, Paemen L, et al. Prevention of interleukin-8-induced mobilization of hematopoietic progenitor cells in rhesus monkeys by inhibitory antibodies against the metalloproteinase gelatinase $B$ (MMP-9). Proc Natl Acad Sci USA. 1999:96:10863-8.

37. Heissig B, Nishida C, Tashiro Y, Sato Y, Ishihara M, Ohki M, et al. Role of neutrophilderived matrix metalloproteinase- 9 in tissue regeneration. Histol Histopathol. 2010;25:765-70.

38. Dutreix J, Girinski T, Cosset JM, Bernard A, Pico J, Baume D, et al. Blood cell kinetics and total body irradiation. Radiother Oncol. 1987;9:119-29.

39. Gialeli C, Theocharis AD, Karamanos NK. Roles of matrix metalloproteinases in cancer progression and their pharmacological targeting. FEBS J. 2011;278:16-27.

40. Heissig B, Hattori K, Dias S, Friedrich M, Ferris B, Hackett NR, et al. Recruitment of stem and progenitor cells from the bone marrow niche requires MMP-9 mediated release of kit-ligand. Cell. 2002;109:625-37.

41. Vu TH, Werb Z. Matrix metalloproteinases: effectors of development and normal physiology. Genes Dev. 2000;14:2123-33.

42. Hoggatt J, Singh P, Tate TA, Chou BK, Datari SR, Fukuda S, et al. Rapid mobilization reveals a highly engraftable hematopoietic stem cell. Cell. 2018;172:191-204.

43. Cottler-Fox MH, Lapidot T, Petit I, Kollet O, DiPersio JF, Link D, et al. Stem cell mobilization. Hematology Am Soc Hematol Educ Program. 2003:419-37.

44. Klein G, Schmal O, Aicher WK. Matrix metalloproteinases in stem cell mobilization. Matrix Biol. 2015;44-46:175-83.

45. Huang H. Matrix metalloproteinase-9 (MMP-9) as a cancer biomarker and MMP-9 biosensors: recent advances. Sensors. 2018;18:3249.

46. Anderlini $P$, Champlin R. Use of filgrastim for stem cell mobilisation and transplantation in high-dose cancer chemotherapy. Drugs. 2002;62:79-88.

47. Singh VK, Romaine PL, Newman VL. Biologics as countermeasures for acute radiation syndrome: where are we now? Expert Opin Biol Ther. 2015;15:465-71.

48. Williams N, Bertoncello I, Jackson H, Arnold J, Kavnoudias H. The role of interleukin 6 in megakaryocyte formation, megakaryocyte development and platelet production. Ciba Found Symp. 1992;167:160-70.

49. Weber J, Yang JC, Topalian SL, Parkinson DR, Schwartzentruber DS, Ettinghausen $\mathrm{SE}$, et al. Phase I trial of subcutaneous interleukin- 6 in patients with advanced malignancies. J Clin Oncol. 1993;11:499-506. 


\section{ACKNOWLEDGEMENTS}

This work was supported, in part, by contracts from Cleveland BioLabs, Inc. and Genome Protection, Inc., to Roswell Park Comprehensive Cancer Center (AVG and $\mathrm{CMB}$ ) and by the National Cancer Institute (NCl) grant P30CA016056 involving the use of Roswell's Laboratory Animal, Flow and Image Cytometry, and Genomics Shared Resources. We thank Liliya Novototskaya for the breeding and maintenance of mouse colonies used throughout this study, Dr. Elena Komarova for her help with manuscript preparation, and Dr. Elizabeth Repasky for her help with editing the manuscript.

\section{AUTHOR CONTRIBUTIONS}

CMB designed the study, performed experiments, analyzed and interpreted the data, and wrote the manuscript; AVG designed the study, analyzed and interpreted the data, and wrote and edited the manuscript; KFG, ARA, NHT, SP, and BMK aided in performing all experiments; IM analyzed and interpreted bioinformatics data; SIA and LGB edited the manuscript.

\section{COMPETING INTERESTS}

AVG is a shareholder of Cleveland BioLabs, Inc. and Genome Protection, Inc., biotech companies that conduct clinical development of entolimod. Parts of this work performed in CMB and AVG labs were funded by contracts from Cleveland BioLabs, Inc. and Genome Protection, Inc. to Roswell Park Comprehensive Cancer Center. The remaining authors declare no competing interests.

\section{ADDITIONAL INFORMATION}

Supplementary information The online version contains supplementary material available at https://doi.org/10.1038/s41420-021-00642-6.

Correspondence and requests for materials should be addressed to Craig $M$. Brackett.

Reprints and permission information is available at http://www.nature.com/ reprints

Publisher's note Springer Nature remains neutral with regard to jurisdictional claims in published maps and institutional affiliations.

(i) Open Access This article is licensed under a Creative Commons Attribution 4.0 International License, which permits use, sharing, adaptation, distribution and reproduction in any medium or format, as long as you give appropriate credit to the original author(s) and the source, provide a link to the Creative Commons license, and indicate if changes were made. The images or other third party material in this article are included in the article's Creative Commons license, unless indicated otherwise in a credit line to the material. If material is not included in the article's Creative Commons license and your intended use is not permitted by statutory regulation or exceeds the permitted use, you will need to obtain permission directly from the copyright holder. To view a copy of this license, visit http://creativecommons.org/licenses/by/4.0/

(c) The Author(s) 2021 